\title{
CORRELATION BETWEEN THE CONCENTRATION OF BISULPHITE BINDING SUBSTANCES IN THE BLOOD AND THE URINARY THIAMIN EXCRETION ${ }^{1}$
}

\author{
By WILLIAM D. ROBINSON,2 DANIEL MELNICK, 3 AND HENRY FIELD, JR. \\ (From the Department of Internal Medicine, University of Michigan, Ann Arbor)
}

(Received for publication December 29, 1939)

Following the demonstration in Peters' laboratory $(1,2)$ of the specific inability of the thiamindeficient pigeon brain to metabolize pyruvic acid, attempts have been made to utilize methods of demonstrating this biochemical dysfunction as a laboratory test for detecting thiamin deficiencies. Thompson and Johnson (3) in 1935 showed an accumulation of pyruvic acid in the blood of thiamin-deficient animals, and a similar accumulation was demonstrated in human beriberi (4). The pyruvic acid values were obtained by estimating the bisulphite-binding capacity of the blood and expressing the results in terms of pyruvic acid. In a later paper Platt and $\mathrm{Lu}$ (5) showed that, although in animals the large increase in bisulphite-binding substances (B.B.S.) in the blood was probably due entirely to pyruvic acid, only a fraction of the B.B.S. in human cases could be accounted for as pyruvic acid when the latter was determined by the specific hydrazone method of Peters and Thompson (1). The elevated B.B.S. values have been observed to return to normal soon after the administration of thiamin $(3,4,5)$. Subsequently, Taylor and associates $(6,7)$ reported that the elevation of blood B.B.S. was not specific for thiamin deficiency but occurred in other diseased conditions. This finding was supported by studies from the same laboratory (8) on the rate of removal of pyruvic acid administered both intravenously and orally. In these studies clinical findings were the sole criteria of thiamin deficiency.

A specific chemical method for the determination of thiamin in the urine (9) and the application of this procedure $(10,11)$ to the diagnosis of thiamin deficiency have been reported by us.

1 The expense of this investigation was defrayed by grants from the Upjohn Company, Kalamazoo, and from the Horace H. Rackham School of Graduate Studies, University of Michigan.

2 Upjohn Fellow in Clinical Research, 1938-1940.

8 Upjohn Fellow in Clinical Research, 1937-1940.
The present report concerns the correlation between the urinary thiamin excretion and the blood B.B.S. in forty-one hospital patients, and during the production of and recovery from an experimental thiamin deficiency in a human subject.

\section{METHODS}

Urinary thiamin. The chemical method based upon the reaction between the vitamin and diazotized p-aminoacetophenone (9) was used. The procedure gives values that are reproducible and accurate within 5 per cent. It is specific for thiamin in urine, even when the patient is receiving a variety of medications. Despite wide physiologic variation in the $\mathrm{pH}$ of urine in vivo, the vitamin is not destroyed so that no attempt has been made to insure the excretion of an acid urine. Although thiamin is present in the organism predominantly in the phosphorylated form, it is excreted in the free state only. For this reason estimations of free thiamin only have been carried out.

Blood bisulphite-binding capacity. Using potassium oxalate as the anti-coagulant, blood was obtained prior to the test dose of thiamin by venipuncture from patients fasting and at rest. The procedure for estimation of the B.B.S. was essentially the same as that used by Taylor and associates (7) and is based upon the iodometric titration method of Clift and Cook (12), using solid disodium phosphate (13), rather than sodium bicarbonate, to liberate the bound bisulphite. Determinations were run in duplicate with blank analyses conducted on the reagents. Because of the small titration volumes, we have preferred to use twice the quantity of proteinfree filtrate recommended by Taylor et al (7) so that each test solution represented $2 \mathrm{cc}$. of initial whole blood. Another modification employed entails the immediate titration of the liberated bisulphite rather than allowing a preliminary five-minute period for dissolving the disodium phosphate. When the reaction was carried out, using pure aqueous solutions with this five-minute period for mixing included, losses of as much as 14 per cent of the added pyruvic acid were observed. The end point at which a definite blue color persists for thirty seconds is not sharp. However, if the $\mathrm{N} / 200$ iodine solution is added in excess and this excess is then titrated back with thiosulphate, the point at which the blue color disappears is easily detected. In our tests we have used both methods of titration in order to obtain a reliable end point. Experiments with crystalline sodium pyruvate prepared by 
the procedure described by Case (14) and added to blood have given recoveries in the neighborhood of 90 per cent of the theoretical values.

In the present study the bisulphite-binding capacity is expressed in terms of the cc. of the N/200 iodine solution used in titrating the liberated bisulphite in $1 \mathrm{cc}$. of blood. Other carbonyl compounds in the blood react like pyruvic acid and are included in the final value obtained. Recent studies $(15,16)$ indicate that pyruvic acid may constitute only a small fraction of the total B.B.S. in the blood. For this reason we prefer to report our results in terms indicative of what was actually done, rather than translate the values to $\mathrm{mgm}$. of pyruvic acid per 100 cc. of blood. 4 No tests were done on patients showing a ketonuria by the standard $\mathrm{FeCl}_{3}$ reaction.

\section{RESULTS}

Standards. A number of analyses of blood samples obtained from members of the hospital staff gave B.B.S. values in the range reported by Taylor and associates (7) for their normal subjects, namely from 0.15 to $0.25 \mathrm{cc}$. of $\mathrm{N} / 200$ iodine per cc. of whole blood. ${ }^{5}$ We have considered values above $0.27 \mathrm{cc}$. of $\mathrm{N} / 200$ iodine per cc. of blood as increased.

Standards for the urinary excretion of thiamin have been derived by the correlation of the urinary thiamin values with the adequacy of the preceding diet in a group of seventy subjects (11). Excretion of less than 60 micrograms by a male, and less than 40 micrograms by a female, during a twenty-four-hour period when the subject is ingesting an adequate diet, is evidence of thiamin subnutrition. Excretion in twenty-four hours of less than 7 per cent of a $5 \mathrm{mgm}$. test dose of thiamin taken orally with a meal by a member of either sex has the same significance. For reasons detailed elsewhere $(10,11)$, significance is attached only to the per cent of the oral test dose excreted by patients who took an inadequate diet or were receiving antacid medication for peptic ulcer on the days of the test.

Correlation of blood B.B.S. and urinary thiamin excretion in hospital patients. The data on twenty-six patients with urinary thiamin values higher than the above minimal standards are presented in Table I. Seven of these (27 per cent) had blood B.B.S. values higher than 0.27 cc.

4 Cc. of $\mathrm{N} / 200$ iodine per cc. of blood $\times 22=\mathrm{mgm}$. pyruvic acid per $100 \mathrm{cc}$. of blood.

5 These values correspond to 3.3 to $5.5 \mathrm{mgm}$. of pyruvic acid per $100 \mathrm{cc}$. of blood.
TABLE I

Bisulphite-binding power of the blood in patients with urinary thiamin excretion in the normal range

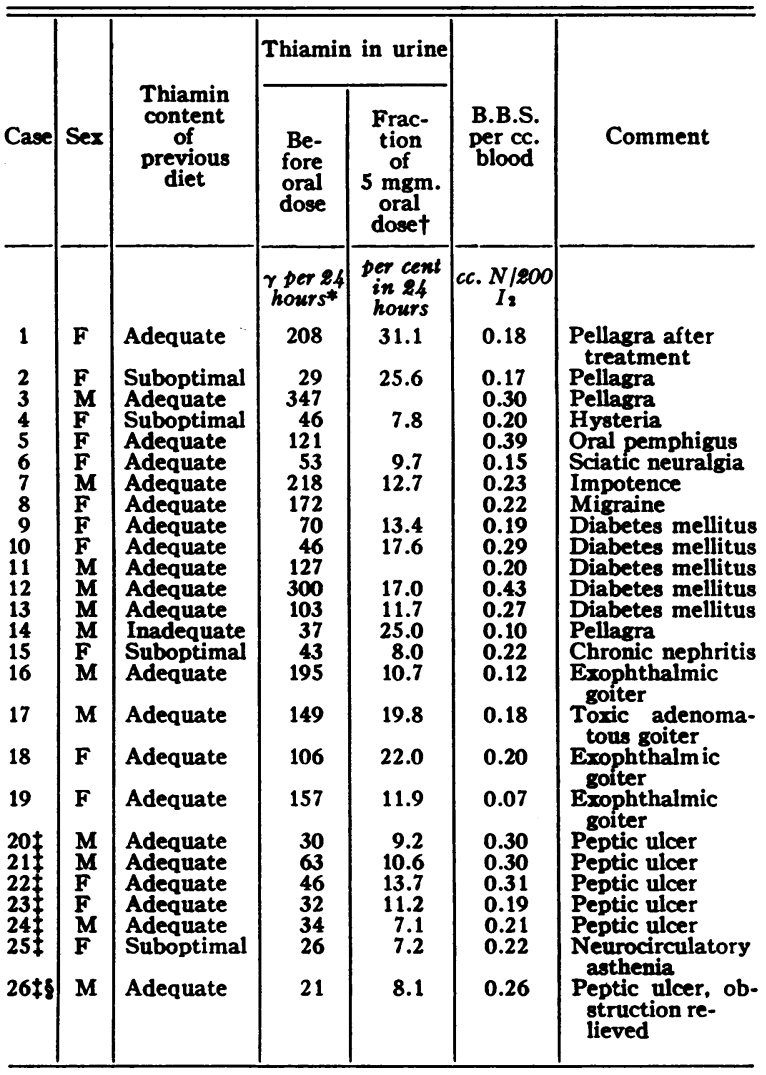

* $\boldsymbol{\gamma}=$ micrograms.

† Values corrected for thiamin from dietary sources excreted during test period.

$\ddagger$ These patients ingested an inadequate diet or were receiving antacid medication for peptic ulcer on the days of the tests. Therefore, significance is attached to urinary thiamin values only after the oral dose $(10,11)$.

\& Data on this case before obstruction was relieved appear in Table II.

$\mathrm{N} / 200$ iodine per cc. of blood. Of these seven, two were patients with controlled diabetes mellitus, and three were patients receiving antacid medications for peptic ulcer. Three other controlled diabetics and three other ulcer patients on the same therapeutic regime had normal blood B.B.S. values.

The results on sixteen patients with urinary thiamin values lower than the minimal standards are presented in Table II. Nine of these (56 per cent) had elevated blood B.B.S. values. The other seven patients with normal values included Case 27 with an alcoholic polyneuritis clinically characteristic of "alcoholic beriberi" which later responded well to thiamin therapy. There is ap- 
TABLE II

Bisulphite-binding power of blood in patients with urinary thiamin excretion indicative of thiamin subnutrition

\begin{tabular}{|c|c|c|c|c|c|c|}
\hline \multirow[b]{2}{*}{ Case } & \multirow[b]{2}{*}{ Sex } & \multirow{2}{*}{$\begin{array}{l}\text { Thiamin } \\
\text { content } \\
\text { of } \\
\text { previous } \\
\text { diet }\end{array}$} & \multicolumn{2}{|c|}{ Thiamin in urine } & \multirow[b]{2}{*}{$\begin{array}{l}\text { B.B.S. } \\
\text { per cc. } \\
\text { blood }\end{array}$} & \multirow[b]{2}{*}{ Comment } \\
\hline & & & $\begin{array}{l}\text { Be- } \\
\text { fore } \\
\text { oral } \\
\text { dose }\end{array}$ & $\begin{array}{c}\text { Frac- } \\
\text { tion } \\
\text { of } \\
5 \mathrm{mgm} . \\
\text { oral } \\
\text { doset }\end{array}$ & & \\
\hline & & & $\begin{array}{l}\gamma \text { per } 24 \\
\text { hours* }\end{array}$ & $\begin{array}{l}\text { per cent } \\
\text { in } 24 \\
\text { hours }\end{array}$ & cc. $\underset{I_{2}}{N / 200}$ & \\
\hline $26 \pm 8$ & $\mathbf{M}$ & Suboptimal & 51 & 1.6 & 0.94 & Obstructing \\
\hline 27 & $\mathbf{M}$ & Inadequate & 19 & 4.3 & 0.23 & Alcoholic \\
\hline $\begin{array}{l}28 \\
29\end{array}$ & $\mathbf{M}$ & $\begin{array}{l}\text { Inadequate } \\
\text { Inadequate }\end{array}$ & $\begin{array}{l}22 \\
38\end{array}$ & & $\begin{array}{l}0.31 \\
0.59 \\
\\
0.30\end{array}$ & $\begin{array}{l}\text { Pellagra } \\
\text { Infected carci- } \\
\text { noma of jaw, } \\
\text { and alcoholism } \\
\text { After thiamin }\end{array}$ \\
\hline 30 & $\mathbf{M}$ & Inadequate & 61 & 1.7 & 0.18 & $\begin{array}{l}\text { Pellagra, scurvy } \\
\text { and atrophic } \\
\text { arthritis }\end{array}$ \\
\hline 31 & $\mathbf{M}$ & Inadequate & 27 & 3.0 & 0.23 & $\begin{array}{c}\text { Pellagra and } \\
\text { cystitis }\end{array}$ \\
\hline 32 & $\mathbf{M}$ & Inadequate & 32 & 3.0 & 0.35 & Carcinoma of jaw \\
\hline 33 & $\mathbf{M}$ & Inadequate & 44 & 2.8 & 0.21 & Exophthalmic \\
\hline 34 & F & Inadequate & 12 & & 0.21 & Hyperemesis \\
\hline $\begin{array}{l}35 \\
36 \\
37 \\
38 \\
39\end{array}$ & $\begin{array}{l}\mathbf{F} \\
\mathbf{M} \\
\mathbf{F} \\
\mathbf{F}\end{array}$ & $\begin{array}{l}\text { Inadequate } \\
\text { Suboptimal } \\
\text { Suboptimal } \\
\text { Suboptimal } \\
\text { Suboptimal }\end{array}$ & $\begin{array}{l}18 \\
19 \\
44 \\
38 \\
17\end{array}$ & $\begin{array}{l}5.5 \\
1.0 \\
2.8 \\
3.4\end{array}$ & $\begin{array}{l}0.29 \\
0.30 \\
0.19 \\
0.23 \\
0.36\end{array}$ & $\begin{array}{l}\text { Pellagra } \\
\text { Heart disease } \\
\text { Myredema } \\
\text { Cirrhosis of liver } \\
\text { Addison's disease }\end{array}$ \\
\hline $\begin{array}{l}408 \\
418\end{array}$ & $\stackrel{\mathbf{F}}{\mathbf{M}}$ & $\begin{array}{l}\text { Suboptimal } \\
\text { Suboptimal }\end{array}$ & $\begin{array}{l}24 \\
26\end{array}$ & $\begin{array}{l}3.8 \\
1.9\end{array}$ & $\begin{array}{l}0.39 \\
0.34\end{array}$ & $\begin{array}{l}\text { Peptic ulcer } \\
\text { Peptic ulcer }\end{array}$ \\
\hline
\end{tabular}

* $\boldsymbol{\gamma}=$ micrograms.

† Values corrected for thiamin from dietary sources excreted during the test period.

$\ddagger$ Data on this case after obstruction was relieved appear in Table $I$.

These patients were receiving antacid medication on days of test; therefore, significance is attached to urinary thiamin values only after the oral dose (11).

parently no critical level of thiamin excretion at which point elevation of the blood B.B.S. occurs.

Three cases have been observed in which there occurred definite reduction of an elevated blood B.B.S. with a change in the nutritional status. Case 26 showed an increase in urinary thiamin and a decrease in the blood B.B.S. to normal levels after the relief of pyloric obstruction by medical treatment which did not include vitamin supplements. Case 29 showed a reduction of the blood B.B.S. after a week of treatment with $25 \mathrm{mgm}$. of thiamin daily. The third patient was a male alcoholic whose urinary thiamin excretion was not determined. When admitted with delirium tremens complicating lobar pneumonia, his blood B.B.S. was 1.05 cc. N/200 iodine per cc. of blood. Eighteen hours after admission, after receiving
$100 \mathrm{mgm}$. of thiamin parenterally, the blood B.B.S. was 0.57 cc., and twenty-four hours later, after additional thiamin, it was $0.30 \mathrm{cc}$. These chemical changes were closely paralleled by the return of the mental state to normal during this period when there was no change in the status of the pulmonary infection.

Blood B.B.S. during experimental thiamin deficiency. The urinary thiamin excretion and the blood B.B.S. values were followed during the production of and recovery from an experimental thiamin deficiency in a previously standardized normal adult. The diet fed during the test period is shown in Table III. It furnished total

TABLE III

Diet used in study of experimental thiamin deficiency

\begin{tabular}{|c|c|c|c|c|c|}
\hline Food & Weight & Thiamin & Calories & $\begin{array}{l}\text { Non- } \\
\text { fat } \\
\text { calories }\end{array}$ & $\frac{\text { Thiamin }}{\begin{array}{c}\text { Non-fat } \\
\text { calorie } \\
\text { ratio }\end{array}}$ \\
\hline $\begin{array}{l}\text { Polished rice .... } \\
\text { White bread..... } \\
\text { Cheddar cheese.. } \\
20 \text { per cent cream } \\
\text { Butter......... } \\
\text { Dextrose....... } \\
\text { Ascorbic acid.... } \\
\text { Nicotinic acid ... }\end{array}$ & $\begin{array}{c}\text { grams } \\
150 \\
240 \\
120 \\
120 \\
60 \\
100 \\
0.1 \\
0.06\end{array}$ & $\begin{array}{c}\text { micro- } \\
\text { grams } \\
45 \\
120 \\
60 \\
42 \\
0 \\
0\end{array}$ & $\begin{array}{l}525 \\
608 \\
550 \\
248 \\
462 \\
400\end{array}$ & $\begin{array}{r}520 \\
580 \\
153 \\
32 \\
0 \\
400\end{array}$ & \\
\hline \multicolumn{2}{|c|}{ Totals........... } & 267 & 2793 & 1685 & 0.16 \\
\hline \multicolumn{2}{|c|}{ Normal control diet ..... } & 860 & 2900 & 1680 & 0.5 \\
\hline
\end{tabular}

Thiamin content calculated from tables compiled by Williams and Spies (17).

calories and non-fat calories at about the same level as did the control diet, but only 30 per cent of the amount of thiamin previously fed. It yielded a thiamin/non-fat calorie ratio of about one-half of that required to prevent the development of beriberi (17). This diet was eaten for thirty-two days.

The results of this experiment are presented in Figure 1. When the deficient diet was begun, the values for urinary thiamin dropped precipitously, and after the third day ranged between 35 and 15 micrograms per twenty-four hours. Throughout this period the blood B.B.S. value did not rise; in fact, there was a slight decrease. Previous control values on this subject ranged from 0.19 to $0.25 \mathrm{cc}$ N/200 iodine per cc. of 


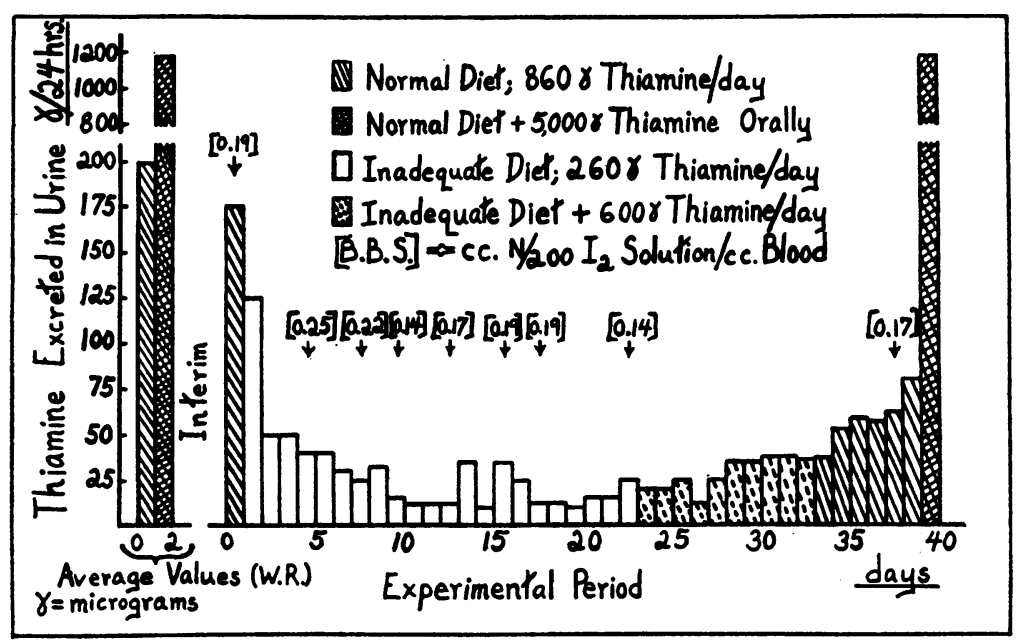

Fig. 1. Urinary Thiamin Excretion and Blood B.B.S. Values During the Production of and Recovery from an Experimental Thiamin DEFICIENCY.

blood. Although the values in Figure 1 were from specimens obtained while fasting and at rest, no change in the blood B.B.S. occurred after prolonged exercise on two occasions during the deficiency period (18).

After twenty-two days, the deficient diet was supplemented for ten days with crystalline thiamin in amounts sufficient to render the total thiamin intake equal to that during the control period. This was followed by six days on the adequate and constant control diet. The urinary thiamin excretion remained at a low level in the range where values for patients with "alcoholic" beriberi had been found (11), and rose very gradually during this period of restitution. No change occurred in the blood B.B.S. concentration after fifteen days of adequate thiamin intake.

The persistence of the low urinary thiamin values after restoration of an adequate thiamin intake demonstrates that the body stores of this vitamin had been depleted during the preceding period of deficient intake. In addition, there were manifestations during the last ten days of deficient intake indicating that an early thiamin deficiency of clinical significance was induced. Aching of the calf muscles after walking was first noted on the twelfth day of the depletion period, and subsequently appeared after progressively decreasing amounts of exercise until it was virtually constant at the end of the test period. This was accompanied during the third week by defi- nite tenderness of the calf muscles and Achilles tendons when they were squeezed, as well as by paresthesias of the lower extremities and dyspnea on mild exertion. These symptoms and findings represented a definite alteration from the control state in this subject. They were constant and progressive in severity from the time of appearance throughout the deficiency period, and gradually disappeared during the first week of thiamin supplementation without any change in activity or diet except the addition of the crystalline vitamin. The neuromuscular manifestations were identical with those described by Strauss (19) as the early manifestations of thiamin deficiency which precede reflex and sensory changes and muscular weakness. The character of these changes and the unexpected rapidity with which they developed corroborated the report of Jolliffe and coworkers (20). It may be significant that their subjects continued their customary activity during the test period, as did ours. We observed no changes in electrocardiograms taken at intervals throughout this experiment $(20,21)$.

\section{DISCUSSION}

In the development of methods for detecting thiamin deficiency, some means of demonstrating the alteration in intermediate carbohydrate metabolism that occurs in this condition should be expected to supplement information gained by determination of urinary thiamin values. The level 
of urinary thiamin excretion cannot in itself indicate more than the degree of aberration from normal nutrition with respect to this dietary essential. The demonstration of a specific biochemical dysfunction would give direct evidence that the thiamin deficiency is causing a metabolic disturbance.

It appears that the blood B.B.S. determination is an unsatisfactory method for demonstrating this "biochemical lesion" of thiamin deficiency. The data in this paper confirm the conclusions from the previously cited clinical studies that an elevation of the blood B.B.S. is not specific for thiamin deficiency. Also important is the fact demonstrated in the present study that patients may have clinical and laboratory evidence of thiamin deficiency and yet have no elevation of the blood B.B.S. Platt and $\mathrm{Lu}$ (5) reported elevated blood B.B.S. values in all of twelve cases of acute fulminating beriberi but in only eight of twenty-nine patients with the subacute form, and in none of three cases of the chronic form of the disease. The problem, at least in this country, is the detection of latent or mild chronic cases of thiamin deficiency, and an easily applicable laboratory procedure is desirable to evaluate such cases. The blood B.B.S. determination lacks both specificity and sensitivity for this purpose. Recent reports by Banerji and Harris (22) indicate that determinations of the urinary bisulphite-binding substances may be significant.

\section{SUMMARY AND CONCLUSIONS}

1. The blood B.B.S. value was elevated in seven of twenty-six patients with normal urinary thiamin excretion.

2. The blood B.B.S. values were normal in seven of sixteen patients with urinary thiamin values indicative of thiamin subnutrition.

3. There was no elevation of the blood B.B.S. value during a twenty-two-day period of grossly inadequate thiamin intake, despite a fall in urinary thiamin excretion to very low levels which persisted after thiamin supplementation, and despite the development of early manifestations of a clinical thiamin deficiency.

4. The determination of the blood B.B.S. value lacks specificity and sensitivity as a means of detecting latent or mild chronic forms of thiamin deficiency.

\section{BIBLIOGRAPHY}

1. Peters, R. A., and Thompson, R. H. S., Pyruvic acid as an intermediary metabolite in the brain tissue of avitaminous and normal pigeons. Biochem. J., 1934, 28, 916.

2. Peters, R. A., The biochemical lesion in vitamin $B_{1}$ deficiency ; application of modern biochemical analysis in its diagnosis. Lancet, 1936, 1, 1161.

3. Thompson, R. H. S., and Johnson, R. E., Blood pyruvate in vitamin $B_{1}$ deficiency. Biochem. J., 1935, 29, 694.

4. Platt, B. S., and Lu, G. D., Intermediate carbohydrate metabolism in vitamin $B_{1}$ deficiency in man. Proc. Chinese Physiol. Soc., Third General Conference, Chinese M. A., 1935, p. 16.

5. Platt, B. S., and Lu, G. D., Chemical and clinical findings in beriberi with special reference to vitamin $B_{1}$ deficiency. Quart. J. Med., 1936, 5, 355.

6. Wilkins, R. W., Taylor, F. H. L., and Weiss, S., Bisulphite binding substances in blood in health and disease, particularly vitamin $B_{1}$ deficiency. Proc. Soc. Exper. Biol. and Med., 1937, 35, 584.

7. Taylor, F. H. L., Weiss, S., and Wilkins, R. W., The bisulphite binding power of the blood in health and in disease with special reference to vitamin $B_{1}$ deficiency. J. Clin. Invest., 1937, 16, 833.

8. Wilkins, R. W., Weiss, S., and Taylor, F. H. L., The effect and rate of removal of pyruvic acid administered to normal persons and to patients with and without "vitamin B deficiency." Ann. Int. Med., 1939, 12, 938.

9. Melnick, D., and Field, H., Jr., Chemical determination, stability and form of thiamine in urine. J. Biol. Chem., 1939, 130, 97.

10. Melnick, D., Field, H., Jr., and Robinson, W. D., A quantitative chemical study of the urinary excretion of thiamine by normal individuals. J. Nutrition, 1939, 18, 593.

11. Robinson, W. D., Melnick, D., and Field, H., Jr., Urinary excretion of thiamin in clinical cases and the value of such analyses in the diagnosis of thiamin deficiency. J. Clin. Invest., 1940, 19, 399.

12. Clift, F. P., and Cook, R. P., A method of determination of some biologically important aldehydes and ketones, with special reference to pyruvic acid and methylyoxal. Biochem. J., 1932, 26, 1788.

13. Elliott, K. A. C., Benoy, M. P., and Baker, Z., The metabolism of lactic and pyruvic acids in normal and tumour tissues. II. Rat kidney and transplantable tumours. Biochem. J., 1935, 29, 1937.

14. Case, E. M., The determination of pyruvic acid. Biochem. J., 1932, 26, 753.

15. Wilkins, R. W., Weiss, S., and Taylor, F. H. L., Relationship of pyruvic acid to the bisulphite binding substances of the blood. Proc. Soc. Exper. Biol. and Med., 1938, 38, 296.

16. Lu, G. D., Studies on the metabolism of pyruvic acid in normal and vitamin $B_{1}$ deficient states. I. A rapid, specific and sensitive method for the esti- 
mation of blood pyruvate. Biochem. J., 1939, 33, 249.

17. Williams, R. R., and Spies, T. D., Vitamin $B_{1}$ (Thia$\mathrm{min}$ ) and its use in medicine. Macmillan and Co., New York, 1938.

18. $\mathrm{Lu}, \mathrm{G}$. D., The metabolism of pyruvic acid in normal and vitamin $B_{1}$ deficient states. II. Blood pyruvate levels in rat, pigeon, rabbit and man; relation of blood pyruvate to cardiac changes. Biochem. J., 1939, 33, 774.

19. Strauss, M. B., The therapeutic use of vitamin $B_{1}$ in polyneuritis and cardiovascular conditions; clinical indications. J. A. M. A., 1938, 110, 953.
20. Jolliffe, N., Goodhart, R., Gennis, J., and Cline, J. $K$., The experimental production of vitamin $B_{1}$ deficiency in normal subjects; dependence of urinary excretion of thiamin on dietary intake of vitamin B $_{1}$. Am. J. M. Sc., 1939, 198, 198.

21. Weiss, S., Haynes, F. W., and Zoll, P. M., Electrocardiographic manifestations and cardiac effect of drugs in vitamin $B_{1}$ deficiency in rats. Am. Heart J., 1938, 15, 206.

22. Banerji, G. G., and Harris, L. J., Methods for assessing the level of nutrition. A carbohydrate tolerance test for vitamin $B_{1}$. I. Experiments with rats. Biochem. J., 1939, 33, 1346. 